\title{
Electron Density Distributions Calculated for the Nickel Sulfides Millerite, Vaesite, and Heazlewoodite and Nickel Metal: A Case for the Importance of Ni-Ni Bond Paths for Electron Transport
}

\author{
G. V. Gibbs, ${ }^{*, \dagger}$ R. T. Downs, ${ }^{\ddagger}$ C. T. Prewitt, $\$$ K. M. Rosso,${ }^{\S}$ N. L. Ross,,$"$ and D. F. Cox ${ }^{\perp}$ \\ Departments of Geosciences, Materials Science and Engineering, Chemical Engineering, and Mathematics, \\ Virginia Tech, Blacksburg, Virginia 24061, Department of Geosciences, University of Arizona, Tucson, \\ Arizona 85721, and William R. Wiley Environmental Molecular Sciences Laboratory, Pacific Northwest \\ National Laboratory, Richland, Washington 99352
}

Received: July 25, 2005; In Final Form: September 20, 2005

\begin{abstract}
Bond paths and the bond critical point properties (the electron density $(\rho)$ and the Hessian of $\rho$ at the bond critical points (bcp's)) have been calculated for the bonded interactions comprising the nickel sulfide minerals millerite, $\mathrm{NiS}$, vaesite, $\mathrm{NiS}_{2}$, and heazlewoodite, $\mathrm{Ni}_{3} \mathrm{~S}_{2}$, and $\mathrm{Ni}$ metal. The experimental $\mathrm{Ni}-\mathrm{S}$ bond lengths decrease linearly as the magnitudes of the properties each increases in value. Bond paths exist between the $\mathrm{Ni}$ atoms in heazlewoodite and millerite for the $\mathrm{Ni}-\mathrm{Ni}$ separations that match the shortest separation in $\mathrm{Ni}$ metal, an indicator that the $\mathrm{Ni}$ atoms are bonded. The bcp properties of the bonded interactions in $\mathrm{Ni}$ metal are virtually the same as those in heazlewoodite and millerite. $\mathrm{Ni}-\mathrm{Ni}$ bond paths are absent in vaesite where the $\mathrm{Ni}-\mathrm{Ni}$ separations are $60 \%$ greater than those in $\mathrm{Ni}$ metal. The bcp properties for the $\mathrm{Ni}-\mathrm{Ni}$ bonded interactions scatter along protractions of the $\mathrm{Ni}-\mathrm{S}$ bond length-bcp property trends, suggesting that the two bonded interactions have similar characteristics. $\mathrm{Ni}-\mathrm{Ni}$ bond paths radiate throughout $\mathrm{Ni}$ metal and the metallic heazlewoodite structures as continuous networks whereas the $\mathrm{Ni}-\mathrm{Ni}$ paths in millerite, a p,d-metal displaying ionic and covalent features, are restricted to isolated $\mathrm{Ni}_{3}$ rings. Electron transport in $\mathrm{Ni}$ metal and heazlewoodite is pictured as occurring along the bond paths, which behave as networks of atomic size wires that radiate in a contiguous circuit throughout the two structures. Unlike heazlewoodite, the electron transport in millerite is pictured as involving a cooperative hopping of the d-orbital electrons from the $\mathrm{Ni}_{3}$ rings comprising $\mathrm{Ni}_{3} \mathrm{~S}_{9}$ clusters to $\mathrm{Ni}_{3}$ rings in adjacent clusters via the p-orbitals on the interconnecting $\mathrm{S}$ atoms. Vaesite, an insulator at low temperatures and a doped semiconductor at higher temperatures, lacks $\mathrm{Ni}-\mathrm{Ni}$ bond paths. The net charges conferred on the $\mathrm{Ni}$ and $\mathrm{S}$ atoms are about a quarter of their nominal charges for the atoms in millerite and vaesite with the net charge on $\mathrm{Ni}$ increasing with increasing $\mathrm{Ni}-\mathrm{S}$ bond length. Reduced net charges are observed on the $\mathrm{Ni}$ atoms in heazlewoodite and are related to its $\mathrm{Ni}-\mathrm{Ni}$ metal bonded interactions and to the greater covalent character of its bonds. Local energy density and bond critical point properties of the electron density distributions indicate that the $\mathrm{Ni}-\mathrm{S}$ and $\mathrm{Ni}-\mathrm{Ni}$ bonded interactions are intermediate in character between ionic and covalent.
\end{abstract}

\section{Introduction}

Metal sulfides are an important class of ore minerals that display a host of interesting bonded interactions and structure types in concert with an assortment of important electronic and magnetic properties. The properties have attracted the attention of solid-state physicists, material scientists, and mineralogists who have determined the crystal and electronic structures for a variety of sulfide minerals and representative clusters. ${ }^{1-10}$ Despite the important information provided by these studies, the understanding of the bond length and bond strength variations, bonded interactions, and the structures of a variety of sulfides is lacking, particularly when contrasted with that of the oxides. This shortcoming has been ascribed to the diversity

* Author to whom correspondence should be addressed. Phone: (540)231-6330. Fax: (540)231-3386. E-mail: gvgibbs@vt.edu.

† Departments of Geosciences, Materials Science and Engineering, and

Mathematics, Virginia Tech.

$\doteqdot$ University of Arizona.

$\S$ Pacific Northwest National Laboratory.

II Department of Geosciences, Virginia Tech.

${ }^{\perp}$ Department of Chemical Engineering, Virginia Tech. of metal-metal $(\mathrm{M}-\mathrm{M})$ and sulfur-sulfur $(\mathrm{S}-\mathrm{S})$ bonded interactions displayed by a number of sulfides together with traditional metal-sulfur $(\mathrm{M}-\mathrm{S})$ bonded interactions displayed by these and by others. ${ }^{1,6,11-13}$ This is in contrast with the oxide minerals where only metal-oxygen $(\mathrm{M}-\mathrm{O})$ interactions are displayed. Suffice it to say, the crystal structures of oxide minerals are comparatively simple, consisting of threedimensional contiguous arrays of corner, edge, and, in some cases, face-sharing $\mathrm{MO}_{n}$ coordinated polyhedra.

During the last century, Pauling's rules ${ }^{14}$ played a pivotal role in advancing the understanding of the bond strength and bond length variations, the structures, and the crystal chemistry of the oxides. ${ }^{15-20}$ However, they proved to be of more limited use in advancing the understanding of the bond strength and bond length variations for the bonded interactions for a number of sulfides. For these structures, the $\mathrm{M}$ atoms are not only bonded to $\mathrm{S}$ atoms in forming $\mathrm{MS}_{n}$ classical coordinated polyhedra, but they also can be bonded to the $\mathrm{M}$ atoms in adjacent coordinated polyhedra, forming a more complicated array of bonded interactions. ${ }^{2,11,12,21}$ As such, the Pauling bond 
strength ${ }^{14}$ of an $\mathrm{M}-\mathrm{S}$ bonded interaction and the coordination number of the $\mathrm{M}$ atom are not well-defined quantities in the sense that they are for the classical coordinated polyhedra in oxides, rendering Pauling's rules ${ }^{14}$ less satisfactory in the determination and the testing of the structures with $\mathrm{M}-\mathrm{M}$ bonded interactions and $\mathrm{S}-\mathrm{S}$ interactions comprising $\mathrm{S}_{2}$ molecules. To our knowledge, no one has established a bond length-bond strength relationship like the ones formulated for the oxides. Lacking a well-defined definition of bond strength, it is evident why less progress has been made in the advancement of the understanding of the bonded interactions, the structures, and the crystal chemistry of the sulfides.

Precise sets of accurate diffraction data were recently recorded for a number of oxides with high-energy synchrotron and highresolution single-crystal X-ray diffraction methods. ${ }^{22-29} \mathrm{~A}$ generalized X-ray scattering factor and multipole modeling of the data ${ }^{30,31}$ yielded model experimental electron density distributions that agree reasonably well with those calculated with theoretical structure factors. The bond critical point (bcp) properties generated for the electron density distributions ${ }^{32}$ likewise agree with those calculated with first-principle methods, typically within $5-10 \% .{ }^{33}$ With the localization of the electron density $\left(\rho\left(r_{\mathrm{c}}\right)\right)$ at $r_{\mathrm{c}}$, and the local concentration of $\rho$, both perpendicular and parallel to the bond path, the experimental bond lengths decrease as the electron density is progressively localized and locally concentrated at $r_{\mathrm{c}}$, and the nuclei of the bonded atoms are progressively shielded. When bond length decreases, the bonded radii of the $\mathrm{O}$ atom decrease, adopting the ionic radius ( $1.40 \AA$ ) when bonded to a highly electropositive atom such as $\mathrm{K}$, the atomic radius $(0.65 \AA)$ when bonded to a highly electronegative atom such as $\mathrm{N}$, and intermediate values when bonded to atoms of intermediate electronegativities. ${ }^{34}$ Also, experimental and theoretical $\rho\left(r_{\mathrm{c}}\right)$ values correlate with the $\mathrm{SiO}$ bond strength, ${ }^{16}$ providing a theoretical underpinning for Pauling's definition of bond strength ${ }^{14}$ and the connection between bond strength and bond length. ${ }^{35}$ A partitioning of the electron density resulted in net atomic charges for the bonded atoms that indicate that the closed-shell ionic character for a given bonded interaction increases with increasing bond length and coordination number.

To our knowledge, the bcp properties for the electron density distribution for a sulfide have yet to be reported. A determination of these properties will not only shed light on the relative strengths and properties of the $\mathrm{M}-\mathrm{S}$ bonded interactions and the net charges of the atoms but also indicate whether $\mathrm{M}-\mathrm{M}$ bonded interactions exist. Our study will be restricted to the three Ni sulfides heazlewoodite, $\mathrm{Ni}_{3} \mathrm{~S}_{2}$, millerite, NiS, vaesite, $\mathrm{NiS}_{2}$, and to bulk Ni metal. In particular, heazlewoodite and millerite were chosen because they contain $\mathrm{Ni}-\mathrm{Ni}$ separations that match the shortest Ni separations in bulk Ni metal, ${ }^{11,12,21}$ vaesite was chosen because it lacks the short separations but contains a $\mathrm{S}-\mathrm{S}$ molecule, and bulk Ni metal was chosen so that its bond paths and $\mathrm{Ni}-\mathrm{Ni}$ bcp properties can be compared with those by the Ni sulfides if present. An important goal will be to determine whether $\mathrm{Ni}-\mathrm{Ni}, \mathrm{S}-\mathrm{S}$, and $\mathrm{Ni}-\mathrm{S}$ bond paths are displayed by the theoretical electron density distributions generated for the three sulfides, an indicator that these atom pairs are bonded. If a line of maximum localized electron density (denoted a bond path) links the nuclei of an atom pair and a surface is formed that defines a mutual boundary of zero flux in $\nabla \rho$ between the pair such that the surface intersects the line at a point where the electron density adopts a local minimum value, $\partial \rho / \partial r=0$, then the pair is indicated to be bonded. The presence of a bond path linking a pair of atoms is a necessary condition for the two to be bonded to one another. ${ }^{36}$ By enumeration of the number and the spatial distribution of the bond paths that radiate from an atom, the architecture of its bonded interactions is uniquely defined.

If bond paths are found to connect the $\mathrm{Ni}$ atoms, then the bcp properties of the $\mathrm{Ni}-\mathrm{Ni}$ bonded interactions will be compared with those displayed by bulk Ni metal. The comparison will improve the understanding of the bonded interactions between the $\mathrm{Ni}$ atoms, the metallic conductivity, and the delocalization of electrons and the structure of heazlewoodite. ${ }^{37}$ They will also clarify why the electron transport behavior exhibited by millerite is related to strong $\mathrm{Ni} \mathrm{d}-\mathrm{S}$ p chargetransfer interactions and an electron-hopping phenomenon between the $\mathrm{Ni}$ and the $\mathrm{S}$ atoms rather than to $\mathrm{Ni}-\mathrm{Ni}$ interactions as exhibited by heazlewoodite ${ }^{8,10}$ and why vaesite is an insulator at low temperatures. ${ }^{38}$ As the mean $\mathrm{Ni}-\mathrm{S}$ bond lengths for heazlewoodite, millerite, and vaesite increase from 2.27 to 2.31 to $2.40 \AA$, respectively, the investigation will show whether the net charges and the metallic character of the $\mathrm{Ni}$ atom correlate with bond length as observed for the $\mathrm{SiO}$ bond. The theoretical electron density distributions will also show the extent to which the experimental $\mathrm{Ni}-\mathrm{S}$ and $\mathrm{Ni}-\mathrm{Ni}$ bond lengths correlate with the bond critical point properties. ${ }^{32}$ If they follow the trends displayed for the oxides, then their magnitudes will increase in value as the experimental bond lengths decrease and as the electron density is localized and locally concentrated in the binding region. An evaluation of the net charges will not only provide an estimate of the valences of the $\mathrm{Ni}$ and $\mathrm{S}$ atoms comprising the nonclassical $\mathrm{Ni}_{3} \mathrm{~S}_{2}$ chemical formula exhibited by heazlewoodite and those for millerite and vaesite, but it will also shed light on the nature of the bonded interactions. We will also see whether the net atomic charges on the $\mathrm{S}$ atoms in millerite and heazlewoodite conform with that on the $\mathrm{S}$ atom comprising the $S_{2}$ molecule in vaesite and whether $S-S$ bond paths exist between the $S$ atoms of adjacent coordination polyhedra for heazlewoodite and millerite. Because the net charges on the Ni atoms in bulk Ni is zero, it will be of interest to see whether the net charge on the $\mathrm{Ni}$ atoms involved in a preponderance of $\mathrm{Ni}-\mathrm{Ni}$ bond paths are smaller than those involved in a preponderance of $\mathrm{Ni}-\mathrm{S}$ bond paths.

\section{Structure and Electronic Properties}

The crystal structures of heazlewoodite, millerite, and vaesite are well-known. ${ }^{12,21,39-41}$ The heazlewoodite structure can be described as a highly distorted, eutactically cubic, close-packed array of S atoms $(a=5.736 \AA, b=5.781 \AA, c=4.072 \AA, \alpha$ $\left.=89.36^{\circ}, \beta=\gamma=90.00^{\circ}\right)$ with three-fourths of the available disphenoid (distorted tetrahedra) voids occupied by Ni. The close-packed (cp) cell is defined in terms of the body-centered cell (bc) determined by Fleet ${ }^{12}$ by $\mathbf{a}_{\mathrm{cp}}=\mathbf{a}_{\mathrm{bc}}-\mathbf{b}_{\mathrm{bc}}, \mathbf{a}_{\mathrm{cp}}=\mathbf{a}_{\mathrm{bc}}+$ $\mathbf{b}_{\mathrm{bc}}$, and $\mathbf{c}_{\mathrm{cp}}=\mathbf{c}_{\mathrm{bc}}$. In the array, three $\mathrm{NiS}_{4}$ distorted tetrahedra share a common edge to form an $\mathrm{Ni}_{3} \mathrm{~S}_{8}$ cluster (Figure 1a). The $\mathrm{Ni}$ atoms in each cluster are $2.53 \AA$ apart, slightly greater than the shortest $\mathrm{Ni}-\mathrm{Ni}(2.49 \AA)$ separation in face-centered cubic bulk $\mathrm{Ni}$ metal, but the separations of the $\mathrm{Ni}$ atoms with those in two adjacent clusters are $2.49 \AA$, statistically identical with those in the bulk metal. The slightly greater $\mathrm{Ni}-\mathrm{Ni}$ separation in the $\mathrm{Ni}_{3} \mathrm{~S}_{8}$ cluster has been ascribed to nonbonded repulsions among the $\mathrm{Ni}$ atoms comprising the three distorted tetrahedra of the cluster that share a common edge. ${ }^{12}$ Also, each $\mathrm{S}$ atom is bonded to six Ni atoms, three at $2.26 \AA$ and three at $2.29 \AA$.

The millerite structure is substantially different from that of heazlewoodite. Each $\mathrm{Ni}$ atom is coordinated by five $\mathrm{S}$ atoms disposed at the corners of a distorted square pyramid, and each 
(a)

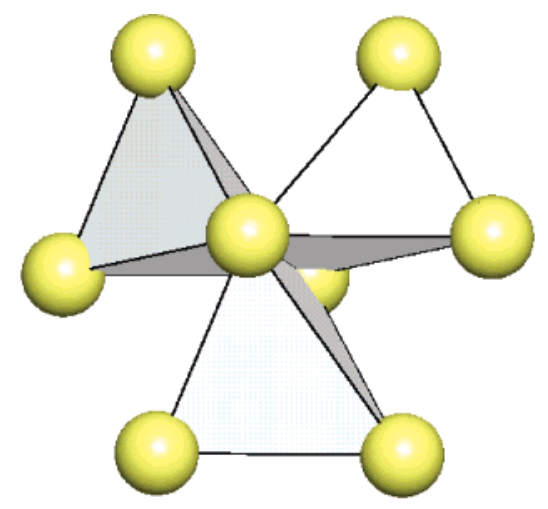

(b)

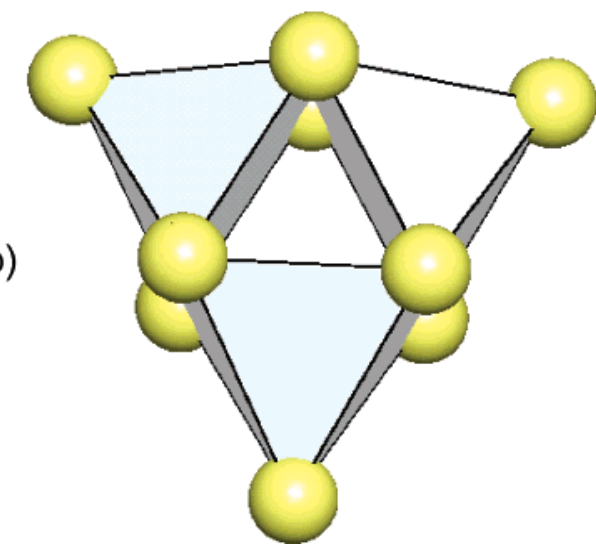

Figure 1. Polyhedral drawings of the (a) $\mathrm{Ni}_{3} \mathrm{~S}_{8}$ cluster in heazlewoodite and the (b) $\mathrm{Ni}_{3} \mathrm{~S}_{9}$ cluster in millerite. The large spheres represent $\mathrm{S}$. The $\mathrm{Ni}$ atoms are not displayed but are enclosed within the polyhedra. The $\mathrm{Ni}$ atoms are coordinated by four $\mathrm{S}$ atoms disposed at the corners of a distorted tetrahedron in heazlewoodite and by five $\mathrm{S}$ atoms disposed at the corners of a square pyramid in millerite.

$\mathrm{S}$ is coordinated by five $\mathrm{Ni}$ atoms likewise disposed at the corners of a distorted square pyramid. Each $\mathrm{NiS}_{5}$ square pyramid shares edges with two adjacent equivalent $\mathrm{NiS}_{5}$ pyramids to form an $\mathrm{Ni}_{3} \mathrm{~S}_{9}$ cluster (Figure 1b) with a $\mathrm{Ni}-\mathrm{Ni}$ separation of $2.53 \AA$, similar to that in $\mathrm{Ni}$ metal and heazlewoodite. The clusters share corners with equivalent clusters and are arranged in a cubic close-packed fashion throughout the structure. The next-nearest $\mathrm{Ni}$ in a neighboring cluster is at a distance of 3.15 $\AA$, substantially greater than the $\mathrm{Ni}-\mathrm{Ni}$ separation in $\mathrm{Ni}$ metal.

Vaesite is isostructural with the well-known mineral pyrite, $\mathrm{FeS}_{2}$. The $\mathrm{Ni}$ atoms in vaesite are arranged in a face-centered array like bulk $\mathrm{Ni}$ metal, but the shortest $\mathrm{Ni}-\mathrm{Ni}$ separations are substantially greater $(4.02 \AA)$ than the shortest separations in the metal. $\mathrm{S}_{2}$ molecules center each octahedral void in the eutactically close-packed array with three $\mathrm{Ni}$ atoms bonded to one of the $\mathrm{S}$ atoms of the $\mathrm{S}_{2}$ molecule and three bonded to the other $\mathrm{S}$ atom, each at a distance of $2.40 \AA$. The $\mathrm{S}-\mathrm{S}$ bond vectors of the $S_{2}$ molecules are oriented in the octahedra perpendicular to the eutactically close-packed $\mathrm{Ni}$ monolayers with a S-S separation of $2.07 \AA$, compared with that (2.08 $\AA$ ) reported for the gas-phase $S_{2}$ molecule. On the basis of this description, the structure of vaesite can be pictured as a stuffed derivative of the Ni metal structure with $\mathrm{S}_{2}$ molecules stuffed in all of the available octahedral voids. It is of interest to determine the atomic charges conferred on the $\mathrm{Ni}$ atoms comprising a fictive neutral $\mathrm{Ni}$ metal structure in vaesite and those on the $\mathrm{S}$ atoms that comprise a fictive neutral $\mathrm{S}_{2}$ molecule.

According to electronic transport experiments, the electrons in heazlewoodite are delocalized throughout the structure to the extent that they are believed to be transported as in a metal. ${ }^{37}$
Room-temperature resistivity measurements bear this out and show that the conductivity for bulk Ni metal is only $\sim 2.5$ times greater than that observed for heazlewoodite. The lower but substantial conductivity displayed by heazlewoodite is consistent with the electronic structure calculations completed by $\mathrm{Lu}$ et al. ${ }^{7}$ that display a metallic band structure and provide a theoretical basis for the $\mathrm{Ni}-\mathrm{Ni}$ bonded interactions. Valence and deformation electron density level line contour maps generated in their analysis display a low-lying uniform distribution of electron density in the interstitial region ascribed to $\mathrm{Ni}-$ $\mathrm{Ni}$ bonded interactions in concert with maxima along the $\mathrm{Ni}-\mathrm{S}$ bond vectors ascribed to shared covalent bonded interactions. However, while the band structure of millerite indicates a metallic character, it is believed that the electrons are localized in a hybridized mixture of $\mathrm{S}$ p,Ni d-type atomic orbitals. On the basis of electronic parameter hopping interaction strengths obtained in electronic structure calculations, Krishnakumar et al. ${ }^{10}$ concluded that millerite is a highly covalent p,d-metal in which electron correlation effects are important as suggested by arguments given by Watanabe and Doniach. ${ }^{42}$ The theory indicates that electron transport involves the hopping of electrons between nearest-neighbor $\mathrm{Ni} d$ and $\mathrm{S} \mathrm{p}$ sites. ${ }^{42}$ However, the conductivity of bulk Ni metal is $\sim 7.5$ times greater than that of millerite.

As observed above, the separations between nearest-neighbor $\mathrm{Ni}$ atoms in vaesite are substantially greater than those in millerite, heazlewoodite, and $\mathrm{Ni}$ metal. Measurements of the conductivity of crystals and powdered samples show that vaesite behaves as an insulator at temperatures below $100 \mathrm{~K}$ and as a doped semiconductor at higher temperatures. ${ }^{38}$ However, at the higher temperatures, the sample conductance is dominated by $\mathrm{Ni}-\mathrm{Ni}$ surface conduction, an effect that has been ascribed to a high density of surface $S_{2}$ molecular vacancies rendering the surface Ni-rich, thereby providing potential pathways for transporting electrons.

As observed above, the bcp properties of the electron density distribution for the sulfides have yet to be evaluated, despite the importance of sulfides as ore minerals and their fascinating conducting and semiconducting properties. However, a carefully determined experimental level line deformation electron density map generated for chalcopyrite, $\mathrm{CuFeS}_{2}$, was found to display maxima along the $\mathrm{FeS}$ and $\mathrm{CuS}$ bond vectors, evidence for shared covalent bonded interactions. ${ }^{9}$ The map also displays a domain of electron density running between the $\mathrm{Fe}$ and the $\mathrm{Cu}$ atoms that suggests the presence of a $\mathrm{CuFe}$ bond path and that the two atoms are bonded. Also, bond paths have been reported between the metals atoms for a number of transition metal complexes where the $\mathrm{M}-\mathrm{M}$ bonded interactions tend to be more directed and stronger than those in metals and alloys. ${ }^{43}$

\section{Calculations of Electronic Structure and Properties}

Electronic structure calculations were completed using the program CRYSTAL98 ${ }^{44}$ The program computes the electronic structure of periodic systems in reciprocal space using Bloch functions expanded as linear combinations of atom-centered Gaussian basis functions. Self-consistent field wave functions were computed for experimental crystal structures at the density functional theory level. We used the local density approximation (LDA) as formulated by the local spin density approximation by Dirac ${ }^{45}$ for the exchange potential and the Vosko-WilkNusair ${ }^{46}$ parametrization of the correlation potential. All electron basis sets specifically optimized for use in the CRYSTAL program were used. For $\mathrm{Ni}$, we used the $86-411(41 \mathrm{~d}) \mathrm{G}$ basis set by Towler ${ }^{47}$ and for $\mathrm{S}$ we used the $86-311 \mathrm{G}^{*}$ basis set by 
Lichanot et al. ${ }^{48}$ Experimental structures used were the Sowa et al. ${ }^{40}$ millerite structure $(P=0.1 \mathrm{MPa})$ and the Parise ${ }^{41}$ heazlewoodite structure. Only limited magnetic structure information is available for these materials. Vaesite is anti-ferromagnetic, but the orientation of the magnetic planes is not wellknown. ${ }^{38}$ Heazlewoodite displays paramagnetism. ${ }^{37}$ Millerite is diamagnetic. ${ }^{10}$ For the purposes of this effort, the LDA calculations were run spin-restricted except for $\mathrm{Ni}$ metal.

The properties of the electron density distributions were generated with the program TOPOND98. ${ }^{49}$ The bond critical points were located using an automated eigenvector-following algorithm performed on finite regions of space with a maximum radius of $6 \AA$ centered on each nonequivalent atom. The bond paths were traced by following the gradient vector field of the distributions starting at the bcp and terminating at the nuclei of the bonded atoms. The $3 \times 3$ Hessian matrices of the second derivatives $\partial^{2} \rho\left(r_{\mathrm{c}}\right) / \partial x_{i} \partial x_{j}$, numerically generated by the finite difference approximation, were constructed for each bcp in terms of an arbitrarily chosen set of Cartesian basis vectors. Eigenvectors for the matrices were found, unitary matrices were generated, and diagonal matrices were found with traces $\nabla^{2} \rho\left(r_{\mathrm{c}}\right)=\lambda_{1}+\lambda_{2}+\lambda_{3}$, where by definition, $\lambda_{1} \leq \lambda_{2} \leq \lambda_{3}$. The ellipticity, $\epsilon=\left(\lambda_{1} / \lambda_{2}-1\right)$, of a bonded interaction is defined by $\lambda_{1}$ and $\lambda_{2}$, the two negative curvatures of $\rho\left(r_{\mathrm{c}}\right)$, that measure the extent to which the electron density is locally concentrated in a plane perpendicular to the bond path. Atomic basin properties were analyzed indirectly using the approach of Keith. ${ }^{50}$ The size of the capture sphere centered on each nonequivalent atom was taken as the distance from the nucleus to the nearest bond critical point in the $\rho$ field that lies on the $\nabla \rho$ zero flux surface, defining the so-called $\beta$ sphere. The number of $\varphi$ and $\theta$ values for angular integration outside the $\beta$ sphere was 30 in both cases. The number of values for radial integration inside the $\beta$ sphere was also 30 .

$\nabla^{2} \rho\left(r_{\mathrm{c}}\right)$ and $\rho\left(r_{\mathrm{c}}\right)$ have been used to classify bond type. ${ }^{56}$ When $\nabla^{2} \rho\left(r_{\mathrm{c}}\right)$ is negative and the value of $\rho\left(r_{\mathrm{c}}\right)$ is relatively large in value, a bonded interaction is classified as shared covalent. However, when $\nabla^{2} \rho\left(r_{\mathrm{c}}\right)$ is positive and the value of $\rho\left(r_{\mathrm{c}}\right)$ is relatively small, it is classified as closed-shell ionic. This classification scheme works well for bonded interactions involving the majority of first row atoms. However, for bonded interactions involving second row $\mathrm{M}$ atoms, $\nabla^{2} \rho\left(r_{\mathrm{c}}\right)$ is typically positive, and it tends to increase with $\rho\left(r_{\mathrm{c}}\right)$ from right to left in the periodic table. Further, for metal $\mathrm{M}$ atoms, characterized by diffuse $n$ s valence electrons, $\rho\left(r_{\mathrm{c}}\right)$ is small, and $\nabla^{2} \rho\left(r_{\mathrm{c}}\right)$ is typically positive and close to zero and therefore often indeterminate. ${ }^{51}$ As such, Macchi and Sironi ${ }^{52}$ concluded that the Bader-Essén ${ }^{56}$ classification strategy cannot be extended in a straightforward way in assessing the character of $\mathrm{M}-\mathrm{X}$ bonded interactions. In an independent study, Espinosa et al. ${ }^{53}$ proposed an alternative classification strategy based on the ratio $\left|V\left(r_{\mathrm{c}}\right)\right| /$ $G\left(r_{\mathrm{c}}\right)$ of the local potential energy $\left(V\left(r_{\mathrm{c}}\right)\right)$ and the kinetic energy $\left(G\left(r_{\mathrm{c}}\right)\right)$ densities. When $\left|V\left(r_{\mathrm{c}}\right)\right| / G\left(r_{\mathrm{c}}\right)$ is greater than 2.0, they classified the interaction as shared covalent, when it is less than 1.0 , they classified it as closed-shell ionic, and when it is between 1.0 and 2.0, they classified it as intermediate between a covalent and an ionic interaction. An unpublished study ${ }^{54}$ of the local energy density and bcp properties for a relatively large number of $\mathrm{M}-\mathrm{O}$ bonded interactions calculated for earth materials and selected molecules was found to be consistent with the constraints employed by Espinosa et al. ${ }^{53}$ in establishing the limits of the $\left|V\left(r_{\mathrm{c}}\right)\right| / G\left(r_{\mathrm{c}}\right)$ ratio for the three bond types.

\section{Bond Critical Point Properties}

Bond paths were found to connect each of the nearestneighbor $\mathrm{Ni}$ and $\mathrm{S}$ atoms for all three sulfides. The bcp properties for these bonded interactions, displayed in Figure 2 and given in Table 1, increase in magnitude with decreasing experimental bond length. Thus, as the electron density is localized at the bcp, it is locally concentrated both perpendicular and parallel to the bond path, resulting in a progressive shortening of the $\mathrm{Ni}-\mathrm{S}$ bond. Well-developed $\mathrm{Ni}-\mathrm{Ni}$ bond paths were also found to exist between $\mathrm{Ni}$ atoms in millerite, heazlewoodite, and $\mathrm{Ni}$ metal, an indicator that the $\mathrm{Ni}$ atoms are bonded. ${ }^{36}$ This involved the pairs of $\mathrm{Ni}$ atoms in both millerite and heazlewoodite with separations comparable with those in Ni metal. However, bond paths are absent between the next-nearest-neighbor $\mathrm{Ni}$ atoms in millerite that have a separation of $3.15 \AA, \sim 25 \%$ greater than the shortest in Ni metal. No $\mathrm{Ni}-\mathrm{Ni}$ bond paths were found for vaesite where the $\mathrm{Ni}-\mathrm{Ni}$ separations $(4.02 \AA)$ are $\sim 60 \%$ greater than those in Ni metal. The bcp properties for the $\mathrm{Ni}-\mathrm{Ni}$ bonded interactions in millerite, heazlewoodite, and $\mathrm{Ni}$ metal fall along protractions of the bcp property $-\mathrm{Ni}-\mathrm{S}$ bond length trends displayed for the $\mathrm{Ni}-\mathrm{S}$ bonded interactions, suggesting that $\mathrm{Ni}-\mathrm{S}$ and $\mathrm{Ni}-$ $\mathrm{Ni}$ bonded interactions have similar bonding characteristics (Figure 2). The $\mathrm{Ni}-\mathrm{S}$ bonded interactions are nearly circular in cross-section with small ellipticity values, typically less than 0.1 , whereas the $\mathrm{Ni}-\mathrm{Ni}$ bonded interactions in the sulfides are slightly more anisotropic in cross-section with ellipticity, $\epsilon$ values, ranging between 0.5 and 0.8 . However, the $\mathrm{Ni}-\mathrm{Ni}$ bonded interactions in $\mathrm{Ni}$ metal are circular in cross-section $(\epsilon$ $=0$ ), consistent with the high point symmetry of its bonds. The Ni-Ni bonded interactions in heazlewoodite and millerite appear to be well directed with a similar value of $\rho\left(r_{\mathrm{c}}\right)$ as observed for bulk Ni metal.

As observed above, the classical coordination number of $\mathrm{Ni}$ increases from 4 in heazlewoodite to 5 in millerite to 6 in vaesite. But on the basis of the bond paths that radiate from the $\mathrm{Ni}$ atoms, the $\mathrm{Ni}$ atoms in heazlewoodite are each bonded to four $\mathrm{S}$ and four $\mathrm{Ni}$ atoms for a coordination number of 8 , whereas the $\mathrm{Ni}$ atoms in millerite are each bonded to two $\mathrm{Ni}$ and five $\mathrm{S}$ atoms for a coordination number of 7 . As the $\mathrm{Ni}$ atom in vaesite is only bonded to six $\mathrm{S}$ atoms, its coordination number is 6 as described above.

\section{Net Atomic Charges and Bond Type}

The net charges conferred on the atoms for the three $\mathrm{Ni}$ sulfides were obtained by partitioning the electron density distributions, as described above, into atomic basins. ${ }^{32,49}$ The integration of density over the ranges of the basins associated with the $\mathrm{Ni}$ and $\mathrm{S}$ atoms was undertaken in the generation of the total number of electrons in the basins. ${ }^{32}$ The atomic net charges displayed by the atoms associated with the basins were found by adding the nuclear charges of the atoms and the number of electrons in the associated basins. The summation of the positive and negative net charges for the basins of the atoms that comprise a single formula unit for the three sulfides yielded a value of $+0.020 e$ for heazlewoodite, $+0.005 e$ for millerite, and $-0.001 e$ for vaesite, each close to zero as expected for electrostatic neutrality considerations, while a summation over the volumes of the basins of the atoms for the unit cells yielded a value of $67.35 \AA^{3}$ for heazlewoodite, $83.98 \AA^{3}$ for millerite, and $184.11 \AA^{3}$ in vaesite in close agreement with unit cell volumes, 67.50, 84.03, and $183.93 \AA^{3}$, respectively. This agreement verifies the accuracy of the integration of the electron density over the range of each basin. The fraction of the unit 

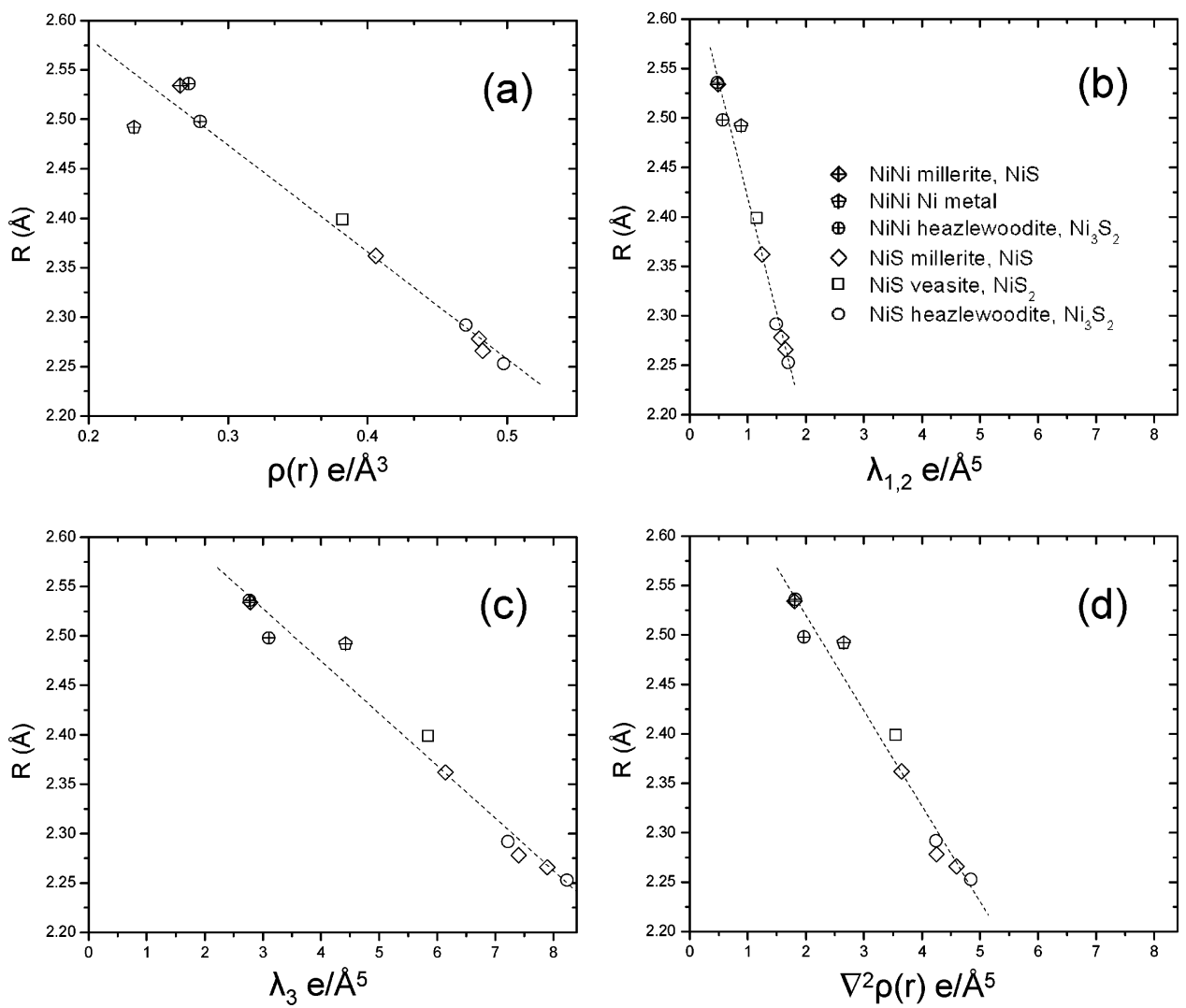

Figure 2. Scatter diagrams of the bond critical point (bcp) properties calculated for the $\mathrm{Ni}-\mathrm{S}$ and $\mathrm{Ni}-\mathrm{Ni}$ bonded interactions in millerite, heazlewoodite, vaesite, and bulk $\mathrm{Ni}$ metal and plotted against the observed bond lengths, $R \AA$. The data are given in Table 1 . The $\mathrm{Ni}-\mathrm{S}$ bcp properties are plotted as open symbols, and the $\mathrm{Ni}-\mathrm{Ni}$ properties are plotted as open symbols with the + symbols. The millerite properties are plotted as a diamonds, the bulk Ni metal properties as pentagons, the heazlewoodite properties as circles, and the vaesite properties as squares. The value of the electron density at the bcp, $\rho\left(r_{\mathrm{c}}\right)$, is plotted in part a, the average curvature of $\rho\left(r_{\mathrm{c}}\right), \lambda_{1,2}$, measured perpendicular to the bond path is plotted in part b, the curvature of $\rho\left(r_{\mathrm{c}}\right), \lambda_{3}$, measured parallel to the bond path is plotted in part c, and the Laplacian of $\rho\left(r_{\mathrm{c}}\right), \nabla^{2} \rho\left(r_{\mathrm{c}}\right)$, is plotted in part d, each as a function of the observed lengths of bonded interactions, $R \AA$. $\lambda_{1,2}$ is a measure of the local concentration of the electron density toward the bond path, and $\lambda_{3}$ is a measure of the local concentration of the electron density toward the bonded atoms, shielding the nuclei of the bonded atoms. The regression analysis coefficient of determination $\left(r^{2}\right)$ is 0.96 for the data displayed in part a and 0.97 for that displayed in parts $\mathrm{b}-\mathrm{d}$.

TABLE 1: Experimental Bond Lengths $(R)$, Electron Density $\left(\rho\left(r_{\mathrm{c}}\right)\right)$, and the Hessian Properties of $\rho\left(r_{\mathrm{c}}\right)$ for the Ni Sulfides and Ni Metal ${ }^{a}$

\begin{tabular}{|c|c|c|c|c|c|c|c|}
\hline & $R$ & $\rho\left(r_{\mathrm{c}}\right)$ & $\nabla^{2} \rho\left(r_{\mathrm{c}}\right)$ & $\lambda_{1}$ & $\lambda_{2}$ & $\lambda_{3}$ & $R(\mathrm{Ni})$ \\
\hline \multicolumn{8}{|c|}{ millerite, $\mathrm{NiS}$} \\
\hline $\mathrm{Ni}-\mathrm{S}$ & 2.266 & 0.482 & 4.597 & -1.658 & -1.639 & 7.894 & 1.064 \\
\hline $\mathrm{Ni}-\mathrm{S}$ & 2.278 & 0.480 & 4.251 & -1.584 & -1.567 & 7.402 & 1.072 \\
\hline $\mathrm{Ni}-\mathrm{S}$ & 2.362 & 0.406 & 3.647 & -1.269 & -1.227 & 6.143 & 1.101 \\
\hline $\mathrm{Ni}-\mathrm{Ni}$ & 2.534 & 0.266 & 1.807 & -0.586 & -0.387 & 2.780 & 1.267 \\
\hline \multicolumn{8}{|c|}{ heazlewoodite, $\mathrm{Ni}_{3} \mathrm{~S}_{2}$} \\
\hline $\mathrm{Ni}-\mathrm{S}$ & 2.253 & 0.497 & 4.844 & -1.732 & -1.655 & 8.231 & 1.063 \\
\hline $\mathrm{Ni}-\mathrm{S}$ & 2.292 & 0.470 & 4.237 & -1.550 & -1.427 & 7.214 & 1.083 \\
\hline $\mathrm{Ni}-\mathrm{Ni}$ & 2.498 & 0.280 & 1.967 & -0.720 & -0.414 & 3.101 & 1.249 \\
\hline $\mathrm{Ni}-\mathrm{Ni}$ & 2.536 & 0.272 & 1.815 & -0.608 & -0.342 & 2.765 & 1.268 \\
\hline$S-S$ & 3.590 & 0.073 & 0.604 & -0.086 & -0.086 & 0.776 & \\
\hline \multicolumn{8}{|c|}{ vaesite, $\mathrm{NiS}_{2}$} \\
\hline $\mathrm{Ni}-\mathrm{S}$ & 2.399 & 0.382 & 3.543 & -1.160 & $\begin{array}{l}138 \\
830\end{array}$ & $\begin{array}{l}5.841 \\
5680\end{array}$ & 104 \\
\hline$S-S$ & 2.072 & 0.795 & 0.011 & -2.839 & -2.839 & 5.689 & \\
\hline \multicolumn{8}{|c|}{ Ni metal } \\
\hline $\mathrm{Ni}-\mathrm{Ni}$ & 2.492 & 0.232 & 2.653 & -0.925 & -0.843 & 4.421 & 1.246 \\
\hline
\end{tabular}

${ }^{a}$ Units are given in Figure 2.

cells occupied by the Ni basins is 0.49 for heazlewoodite, 0.37 in millerite, and 0.24 for vaesite. Hence, heazlewoodite consists of 49 vol $\% \mathrm{Ni}$, millerite 37 vol $\% \mathrm{Ni}$, and vaesite 24 vol \% $\mathrm{Ni}$, indicating that the $\mathrm{Ni}$ metal component is largest for heazlewoodite where the electrons are delocalized as in a metal, intermediate for millerite where the electrons are hybridized as a p,d-metal with features intermediate between ionic and covalent, and the lowest for vaesite, a bulk insulator where the $\mathrm{Ni}$ atoms are separated at $4.02 \AA$.

The net atomic charges on the $\mathrm{Ni}$ atoms increase from $+0.31 e$ (heazlewoodite) to $+0.45 e$ (millerite) to $+0.52 e$ (vaesite) as the $\mathrm{Ni}-\mathrm{S}$ bond lengths increase from 2.27 to 2.31 to $2.40 \AA$, respectively. The increase of the net charge on an $\mathrm{M}$ atom with increasing bond length has also been observed for several oxides. For example, the net charges on the $\mathrm{Mg}$ atoms in the $\mathrm{M}_{1} \mathrm{O}_{6}$ and $\mathrm{M}_{2} \mathrm{O}_{6}$ octahedra comprising forsterite, $\mathrm{Mg}_{2} \mathrm{SiO}_{4}$, increase from $+1.62 e$ to $+1.66 e$ as the mean $\mathrm{MgO}$ bond lengths increase from 2.09 to $2.13 \AA$. The net atomic charge on the $\mathrm{Si}$ atom also increases from +3.17 e for forsterite with a mean $\mathrm{SiO}$ bond length of $1.634 \AA$ to $+3.39 e$ for stishovite, $\mathrm{SiO}_{2}$, with a bond length of $1.774 \AA .{ }^{23,29}$ Accordingly, as asserted by Gibbs et al., 55 the magnitude of net charges on $\mathrm{O}$ atoms increase with increasing bond length (forsterite, $Q(\mathrm{O})=-1.55 e$; stishovite, $Q(\mathrm{O})=-1.69 e)$. In contrast, Aubert et al. ${ }^{26}$ reported that the net charges on the $\mathrm{O}$ atoms for the POAl angles comprising the molecular sieve $\mathrm{AlPO}_{4}-15$ decrease in magnitude from $-1.55 e$ to $-1.51 e$ as the $\mathrm{PO}$ bonds increase in length from 1.51 to $1.55 \AA$, respectively, and as the POAl angle narrows. The net charges on the $\mathrm{S}$ atoms in heazlewoodite $(-0.46 e)$ and millerite $(-0.45 e)$ are similar but substantially larger than that for the $S_{2}$ molecule in vaesite $(-0.26 e)$. However, the global charge on the molecule is -0.53 , comparable to the charges on the $\mathrm{S}$ atoms for the other two. The charge on the $S_{2}$ molecule 
also matches that on the $\mathrm{Ni}$ atoms $(+0.53 e)$ that comprise the cubic face-centered array of $\mathrm{Ni}$ atoms in vaesite. The resulting formulas become $\mathrm{Ni}_{3}{ }^{0.31+} \mathrm{S}_{2}{ }^{0.46-}, \mathrm{Ni}^{0.45+} \mathrm{S}^{0.45-}$, and $\mathrm{Ni}^{0.53+}\left(\mathrm{S}_{2}\right)^{0.53-}$ for heazlewoodite, millerite, and vaesite, respectively. The net charges on the $\mathrm{S}$ atoms for these sulfides do not show a welldeveloped trend with bond length. It is apparent that the magnitudes of the charges on the $\mathrm{Ni}$ atoms in millerite and vaesite and the $\mathrm{S}$ atoms in millerite and heazlewoodite are roughly about a quarter that of the nominal formal valences of two, implying that the character of the bonded interactions has a substantial component of shared covalent character despite the fact that the Laplacian of the interactions is positive, a result that indicates that the bonded interactions are closed-shell ionic for first row elements. ${ }^{56}$ However, the net charge on the $\mathrm{Ni}$ atom in heazlewoodite is smaller, reflecting the greater preponderance of its $\mathrm{Ni}-\mathrm{Ni}$ metal bonded interactions and their greater covalency.

As observed above, as metals are characterized by a diffuse distribution of $n$ s valence electrons, the value of $\nabla^{2} \rho\left(r_{\mathrm{c}}\right)$ is often zero or slightly positive, and $\rho\left(r_{\mathrm{c}}\right)$ is relatively small for $\mathbf{M}-\mathbf{M}$ and $\mathrm{M}-\mathrm{X}$ bonded interactions. ${ }^{52}$ As such, both $\mathrm{M}-\mathrm{M}$ and covalent $\mathrm{M}-\mathrm{X}$ interactions show local concentration features of $\rho$ in the bonding region that are characteristic of closedshell ionic interactions despite their shared covalent character. ${ }^{51,52}$ The small values of $\rho\left(r_{\mathrm{c}}\right)$ and $\nabla^{2} \rho\left(r_{\mathrm{c}}\right)$ calculated for the $\mathrm{Ni}-\mathrm{Ni}$ bonded interactions in millerite and heazlewoodite $\left(\sim 0.27 e \AA^{-3}\right.$ and $\sim 1.86 e \AA^{-5}$ respectively) and Ni metal $(0.232 e$ $\AA^{-3}$ and $2.653 e \AA^{-5}$ respectively) conform with these closedshell characteristics. A calculation of the local kinetic, $G\left(\mathbf{r}_{\mathrm{c}}\right)$, and potential energy, $V\left(\mathbf{r}_{\mathrm{c}}\right)$, densities for the $\mathrm{Ni}-\mathrm{S}$ and $\mathrm{Ni}-\mathrm{Ni}$ bonded interactions for the three $\mathrm{Ni}$ sulfides and $\mathrm{Ni}$ metal resulted in $\left|V\left(\mathbf{r}_{\mathrm{c}}\right)\right| / G\left(\mathbf{r}_{\mathrm{c}}\right)$ ratios that range between 1.20 and 1.26 for the $\mathrm{Ni}-\mathrm{S}$ interactions, a ratio of 1.28 for $\mathrm{Ni}-\mathrm{Ni}$ interactions in $\mathrm{Ni}$ metal, and ratios that range between 1.30 and 1.36 for the $\mathrm{Ni}-\mathrm{Ni}$ interactions in the $\mathrm{Ni}$ sulfides. Also, as expected, the $\left|V\left(r_{\mathrm{c}}\right)\right| / G\left(r_{\mathrm{c}}\right)$ ratio increases from $\sim 1.20$ to $\sim 1.26$ as the net charge on $\mathrm{Ni}$ decreases from $+0.52 e$ to $+0.31 e$, as the $\mathrm{Ni}-\mathrm{S}$ bonds shorten and as the covalent character of the $\mathrm{Ni}-\mathrm{S}$ bonds increases. According to the Espinosa et al. ${ }^{53}$ classification strategy, these ratios indicate that the bonded interactions are intermediate in character between closed-shell ionic and shared covalent. As such, the $\mathrm{Ni}-\mathrm{Ni}$ bonded interactions are viewed as metallic with features intermediate between ionic and covalent as observed for the $\mathrm{Mn}-\mathrm{Mn}$ bonded interactions in $\mathrm{Mn}_{2}$ $(\mathrm{CO})_{10} \cdot{ }^{57}$ Cremer and Kraka ${ }^{58}$ likewise state that the character of a bond depends on whether $V\left(\mathbf{r}_{\mathrm{c}}\right)$ or $G\left(\mathbf{r}_{\mathrm{c}}\right)$ dominates at the bcp of the bonded interaction. When the local total energy, $H\left(\mathbf{r}_{\mathrm{c}}\right)$ $=V\left(\mathbf{r}_{\mathrm{c}}\right)+G\left(\mathbf{r}_{\mathrm{c}}\right)$, is negative and $V\left(\mathbf{r}_{\mathrm{c}}\right)$ dominates, the bond is considered to be covalent; when positive, it is considered to be ionic. As $H\left(\mathbf{r}_{\mathrm{c}}\right)$ is negative but small in magnitude for each of the bonded interactions $\left(\mathrm{Ni}-\mathrm{S},-24\right.$ to $-42 \mathrm{~kJ} /\left(\mathrm{mol} a_{0}{ }^{3}\right)$; Ni$\mathrm{Ni}-27$ to $-31 \mathrm{~kJ} /\left(\mathrm{mol} a_{0}^{3}\right)$, the bonded interactions in the $\mathrm{Ni}$ sulfides are indicated to be intermediate in character, consistent with the Espinosa et al. ${ }^{53}$ classification as intermediate with features between ionic and covalent. Accordingly, the interactions do not appear to qualify as highly covalent as assumed by earlier workers.

\section{Bonded Radii}

The bonded radii of the Ni atoms (Table 1) involved in $\mathrm{Ni}-$ $\mathrm{Ni}$ bonded interactions comprising the three $\mathrm{Ni}$ sulfides are larger $(1.25-1.26 \AA)$ than those involved in $\mathrm{Ni}-\mathrm{S}$ bonded interactions $(1.05-1.10 \AA)$. However, the Ni metal bonded radii match that for Ni metal almost exactly while the radius of the

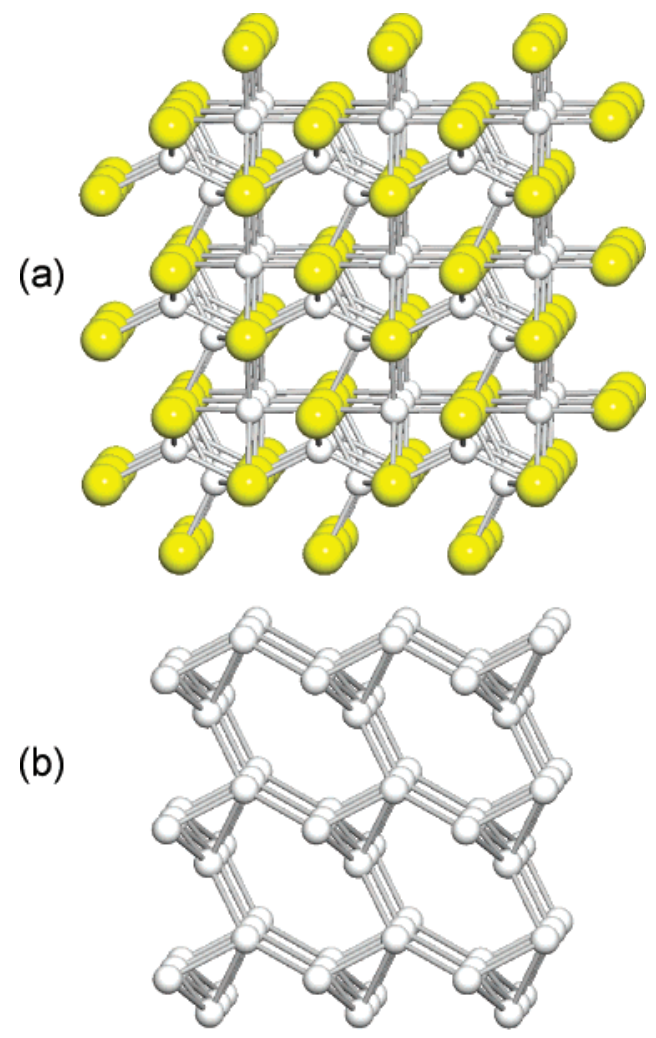

Figure 3. (a) Heazlewoodite structure viewed a few degrees from [001]. The small spheres represent $\mathrm{Ni}$ atoms, and the large spheres represent $\mathrm{S}$ atoms. The lines constructed between the $\mathrm{Ni}$ and $\mathrm{S}$ atoms and the $\mathrm{Ni}$ atoms represent the bond paths that exist between the atoms, denoting the atoms that are bonded. (b) Network of $\mathrm{Ni}-\mathrm{Ni}$ bond paths in heazlewoodite obtained by deleting all of the $\mathrm{S}$ atoms displayed in part a. Four Ni-Ni bond paths radiate from each $\mathrm{Ni}$ atom and form a contiguous array of $\mathrm{Ni}-\mathrm{Ni}$ bond paths that occur throughout the entire structure, forming an ideal circuit for electron transport.

atom comprising the $\mathrm{Ni}-\mathrm{S}$ bonded interactions is substantially larger than the crystal radius ${ }^{59}(0.84 \AA)$ of $\mathrm{Ni}^{2+}$, as expected given its smaller valence of $\sim 1 / 2$. Seven bond paths radiate from each $\mathrm{S}$ atom in heazlewoodite, six involving $\mathrm{Ni}$ atoms and one involving a $\mathrm{S}$ atom in an adjacent $\mathrm{Ni}_{3} \mathrm{~S}_{8}$ cluster. The $\mathrm{S}-\mathrm{S}$ bonded interaction parallels [111] and connects the $\mathrm{Ni}_{3} \mathrm{~S}_{8}$ clusters at a distance of $3.59 \AA$ (Figure 5). The bonded radii of the $\mathrm{S}$ atoms involved in $\mathrm{Ni}-\mathrm{S}$ bonded interactions increase linearly with bond length from 1.202 to $1.262 \AA$ as the observed $\mathrm{Ni}-\mathrm{S}$ bond lengths increase from 2.266 to $2.362 \AA$. These radii are substantially smaller than the crystal radius of the $\mathrm{S}^{2-}$ anion (1.70 $\AA$ ) determined by Shannon. ${ }^{60}$ Equating the volume of the $\mathrm{S}$ basin to that of a sphere, a larger radius of $1.94 \AA$ is obtained. The value of $\rho\left(r_{\mathrm{c}}\right)$ for the $\mathrm{S}_{2}$ molecule in vaesite is $0.79 e \AA^{-3}$ whereas it is $0.07 e \AA^{-3}$ for the two bonded $\mathrm{S}$ atoms in heazlewoodite. The bonded radius for the $\mathrm{S}$ atoms of the $\mathrm{S}_{2}$ molecule $(1.04 \AA)$ in vaesite is the same as that observed for the gas-phase $S_{2}$ molecule, but it is substantially smaller than the separation between the bonded $\mathrm{S}-\mathrm{S}$ atoms in heazelwoodite (1.80 А).

\section{Discussion}

The high metallic conductivity of heazlewoodite can be related to the presence of four well-developed $\mathrm{Ni}-\mathrm{Ni}$ bond paths that radiate from each $\mathrm{Ni}$ atom in the structure, connecting the $\mathrm{Ni}$ atoms in a highly branched circuit of bond paths (Figure 3). The end result is a crystal that can be pictured as wired with $\mathrm{Ni}-\mathrm{Ni}$ bond paths of localized electron density that radiate 
(a)

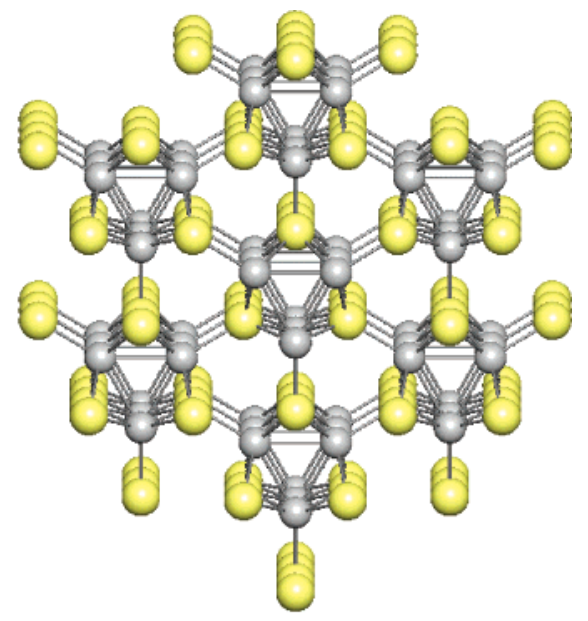

(b)

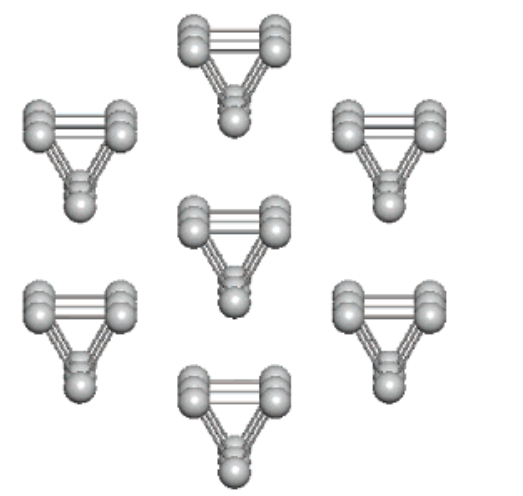

Figure 4. (a) Millerite structure viewed a few degrees from [001]. See legend of Figure 3 for a description. (b) Isolated $\mathrm{Ni}_{3}$ rings that comprise the $\mathrm{Ni}_{3} \mathrm{~S}_{9}$ clusters obtained by deleting the $\mathrm{S}$ atoms displayed in part a. The $\mathrm{Ni}$ atoms of the rings are connected to adjacent $\mathrm{Ni}_{3}$ rings by the $\mathrm{S}$ atoms of the $\mathrm{Ni}_{3} \mathrm{~S}_{9}$ clusters.

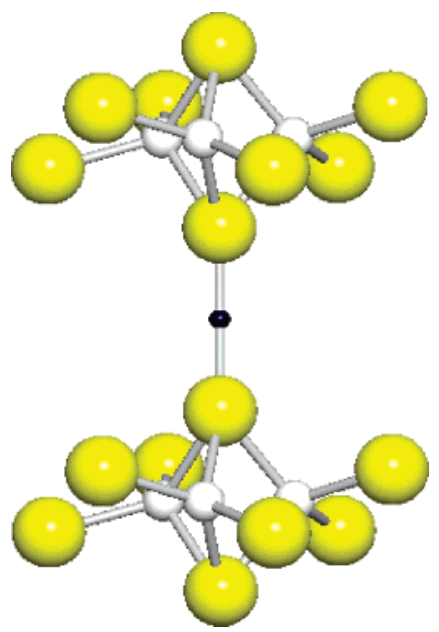

Figure 5. $\mathrm{S}-\mathrm{S}$ bonded interaction connecting adjacent $\mathrm{Ni}_{3} \mathrm{~S}_{8}$ clusters in heazlewoodite. The descriptions of the $\mathrm{Ni}$ and $\mathrm{S}$ atoms are given in the legend to Figure 1. The bcp for the $\mathrm{S}-\mathrm{S}$ interaction is represented by the small solid black circle connected to the two sulfur atoms by a bond path. The $S-S$ bond vector parallels [111] with a $S-S$ separation of $3.59 \AA$..

throughout the crystal, ideally suited for the transport of electrons. In addition, $12 \mathrm{Ni}-\mathrm{Ni}$ bond paths radiate from each $\mathrm{Ni}$ atom in $\mathrm{Ni}$ metal also forming a contiguous network of $\mathrm{Ni}-$ Ni paths throughout the crystal, well-suited for potential electron transport. As such, both Ni metal and heazlewoodite can be pictured as consisting of atomic size wires for electron transport, consistent with their good metallic properties. It is noteworthy that the number of $\mathrm{Ni}-\mathrm{Ni}$ bond paths in heazlewoodite is onethird the number of bond paths in Ni metal while the conductivity of heazlewoodite is about one-third that of $\mathrm{Ni}$ metal. However, the $\mathrm{Ni}-\mathrm{Ni}$ bond paths displayed for millerite are restricted to a three-member $\mathrm{Ni}_{3}$ ring that forms closed circuits of $\mathrm{Ni}-\mathrm{Ni}$ bond paths of localized electron density comprising a $\mathrm{Ni}_{3} \mathrm{~S}_{9}$ cluster (Figure 4). None of the bond paths in the ring is connected to the $\mathrm{Ni}$ atoms in adjacent $\mathrm{Ni}_{3}$ rings. However, rings are interconnected via coordinating $\mathrm{S}$ atoms that link the $\mathrm{Ni}_{3} \mathrm{~S}_{9}$ clusters into a framework of $\mathrm{Ni}-\mathrm{S}$ composition. Unlike the metallic $\mathrm{Ni}-\mathrm{Ni}$ conductivity of $\mathrm{Ni}$ metal and heazlewoodite, the electron transport of millerite is considered to be related to strong Ni d-S p charge-transfer interactions. Electron hopping occurs between nearest-neighbor $\mathrm{Ni}$ and $\mathrm{S}$ atoms where the d-type orbital electrons in the three-membered Ni rings comprising the $\mathrm{Ni}_{3} \mathrm{~S}_{9}$ clusters are pictured as hopping in tandem to adjacent rings via the p-type orbitals on the coordinating $\mathrm{S}$ atoms. As such, the electron transport for millerite is expected to be good, as observed, but not as good as that in heazlewoodite. As noted above, the low volume percentage of Ni atoms in vaesite, its lack of $\mathrm{Ni}-\mathrm{Ni}$ bond paths, and the larger separation between its next-nearest-neighbor $\mathrm{Ni}$ atoms (4.02 $\AA$; a greater hopping distance) compared with that $(3.15 \AA)$ between the $\mathrm{Ni}$ atoms comprising the $\mathrm{Ni}_{3}$ rings in millerite are consistent with its nonconducting properties. Finally, we recognize that the conductivity of a real Ni sulfide is not only related to the degree of the connectivity of the $\mathrm{Ni}-\mathrm{Ni}$ bond paths but that it is also related to such factors as impurity scattering, grain boundaries, and thermal scattering, important factors utterly ignored in our calculations.

Acknowledgment. The National Science Foundation and the U. S. Department of Energy are thanked for supporting this study in part with Grant Nos. EAR-0229472 (N.L.R., G.V.G.), DE-FG02-03ER15389 (J. D. Rimstidt, G.V.G.), and DE-FG0297ER14751 (D.F.C.). This research was performed in part using the Molecular Science Computing Facility in the William R. Wiley Environmental Molecular Sciences Laboratory, a national scientific user facility sponsored by the U. S. Department of Energy's Office of Biological and Environmental Research and located at the Pacific Northwest National Laboratory. Pacific Northwest is operated for the Department of Energy by Battelle. This paper was written in part when G.V.G. was a Visiting Professor at the University of Arizona. Bob Downs is thanked for making available funds to defray some of the costs of the visit. Professor Richard Bader of the Chemistry Department at McMaster University is thanked for his encouraging remarks regarding our picturing of the bond paths in heazlewoodite as avenues of electron transport, Professor Bob Stewart of the Chemistry Department at Carnegie Melon University is thanked for reading the manuscript and making several suggestions that improved the manuscript, and Professor Alfred Ritter of the Physics Department at Virginia Tech is thanked for helping us understand the metal-insulator transitions for the Ni sulfides within the framework of a strongly correlated two-band Hubbard model. We also thank the two anonymous reviewers for their suggestions and comments that improved the paper and for bringing to our attention several important papers on the nature of $\mathrm{M}-\mathrm{M}$ bonding in organometallic compounds.

\section{References and Notes}

(1) Prewitt, C. T.; Rajamani, V. In Sulfide Mineralogy; Mineralogical Society of America: Washington, DC, 1974; Vol. 1, p PR-1.

(2) Wuensch, B. J. In Sulfide Crystal Chemistry; Mineralogical Society of America: Washington, DC, 1974; Vol. 1, p W-21. 
(3) Vaughan, D. J. Bull. Minéral. 1978, 101, 284

(4) Vaughan, D. J.; Craig, J. Mineral Chemistry of Metal Sulfides; Cambridge University Press: Cambridge, U. K., 1978.

(5) Vaughan, D. J.; Tossell, J. A. Phys. Chem. Miner. 1983, 9, 253

(6) Tossell, J. A.; Vaughan, D. J. Theoretical Geochemistry: Applications of Quantum Mechanics in the Earth and Mineral Sciences; Oxford University Press: Oxford, U. K., 1992.

(7) Lu, Z. W.; Klein, B. M.; Singh, D. J. Phys. Rev. B 1996, 54, 13542.

(8) Raybaud, R.; Hafner, J.; Kresse, G.; Toulhoat, H. J. Phys.: Condens. Matter 1997, 9, 11107. 579.

(9) Hall, S. R.; Stewart, J. M. Acta Crystallogr., Sect. B 2001, 297,

(10) Krishnakumar, S. R.; Shanthi, N.; Sarma, D. D. Phys. Rev. B 2002, $66,115105$.

(11) Fleet, M. E. Acta Crystallogr., Sect. B 1972, 28, 1237.

(12) Fleet, M. E. Am. Mineral. 1977, 62, 341.

(13) Sapra, S.; Shanthi, N.; Sarma, D. D. Phys. Rev. B 2002, 66, 205202.

(14) Pauling, L. J. Am. Chem. Soc. 1929, 51, 1010.

(15) Baur, W. H. Trans. Am. Crystallogr. Assoc. 1970, 6, 129. 266.

(16) Brown, I. D.; Shannon, R. D. Acta Crystallogr., Sect. A 1973, 29,

(17) O’Keeffe, M.; Brese, N. E. Acta Crystallogr., Sect. B 1991, 47, 192 .

(18) O'Keeffe, M. In Modern Perspectives in Inorganic Chemistry; Parthe, E., Ed.; Kluwer: Norwell, MA, 1992; p 163.

(19) Mohri, F. Acta Crystallogr., Sect. B 2000, 56, 626.

(20) Brown, I. D. The Chemical Bond in Inorganic Chemistry: The Valence Bond Model; Oxford University Press: Oxford, U. K., 2002.

(21) Rajamani V.; Prewitt, C. T. Can. Mineral. 1974, 12, 253

(22) Lippmann T.; Schneider, J. R. Acta Crystallogr., Sect. A 2000, 56, 575

(23) Kirfel, A.; Krane, H. G.; Blaha, P.; Schwarz, K.; Lippmann, T. Acta Crystallogr., Sect. A 2001, 57, 663.

(24) Kirfel A.; Lippmann, T. HASYLAB Annual Report 2002. http:// www-hasylab.desy.de/science/annual_reports/2002_report/index.html.

(25) Lippmann, T.; Blaha, P.; Anderson, N. H.; Poulsen, H. F.; Wolf, T.; Schneider, J. R.; Schwarz, K. H. Acta Crystallogr., Sect. A 2003, 59, 437.

(26) Aubert, A.; Porcher, F.; Souhassou, M.; Lecomte, C. Acta Crystallogr., Sect. B 2003, 59, 687.

(27) Gibbs, G. V.; Whitten, E. W.; Spackman, M. A.; Stimpfl, M. Downs, R. T.; Carducci, M. D. J. Phys. Chem. B 2003, 107, 12996.

(28) Whitten, A. E.; Dittrich, B.; Spackman, M. A.; Turner, P.; Brown,

T. C. J. Chem. Soc., Dalton Trans. 2004, 23.

(29) A. Kirfel, A.; T. Lippmann, T.; P. Blaha, P.; K. Schwarz, K.; D. F. Cox, D. F.; K. M. Rosso, K. M.; and G. V. Gibbs, G. V. Phys. Chem. Miner. 2005, 32, 301.

(30) Stewart, R. F. J. Chem. Phys. 1969, 51, 4569.

(31) Stewart, R. F. Acta Crystallogr., Sect. A 1976, 32, 565.

(32) Bader, R. F. W. Atoms in Molecules; Oxford Science Publications Oxford, U. K., 1990.
(33) Gibbs, G. V.; Cox, D. F.; Rosso, K. M.; Kirfel, A.; Lippmann, T.; Blaha, P.; Schwarz, K. Phys. Chem. Miner. 2005, 32, 114.

(34) Gibbs, G. V.; Boisen, M. B.; Beverly, L. L.; Rosso, K. M. In Molecular Modeling Theory: Applications in the Geosciences; Cygan, R. T., Kubicki, J. D. Eds.; Reviews in Mineralogy and Geochemistry 42; Mineralogical Society of America: Washington, DC, 2001; p 331.

(35) Gibbs, G. V., Cox, D. F.; Rosso, K. M. J. Phys. Chem. A 2004 108,7643

(36) Bader, R. F. W. J. Phys. Chem. A 1998, 102, 7314

(37) Metcaf, P. A.; Crooker, B. C.; McElfresh, M.; Kakol, Z.; Honig, J. M. Phys. Rev. B 1994, 50, 2055.

(38) Thio, T.; Bennett, J. W. Phys. Rev. B 1994, 50, 10574.

(39) Grice, J. D.; Ferguson, R. B. Can. Mineral. 1974, 12, 248.

(40) Sowa, H.; Ahsbah, H.; Schmidt, W. Phys. Chem. Miner. 1981, 31 321.

(41) Parise, J. B. Acta Crystallogr., Sect. B 1980, 36, 1179.

(42) Watanabe, H.; Doniach, S. Phys. Rev. B 1998, 57, 3829.

(43) Koritsanszky, T. S.; Coppens, P. Chem. Rev. 2001, 101, 1583.

(44) Saunders: V. R.; Dovesi, R.; Roetti, C.; Causá, M.; Harrison, N. M.; Orlando, R.; Aprá, E. CRYSTAL98 User's Manual; University of Torino: Torino, Italy, 1998.

(45) Dirac, P. A. M. The Principles of Quantum Mechanics; Oxford University Press: Oxford, U. K., 1958.

(46) Vosko, S. H.; Wilk, L.; Nusair, M. Can. J. Phys. 1980, 58, 1200.

(47) Towler, M. D. Phys. Rev. B 1994, 50, 5041.

(48) Lichanot, A.; Apra, E.; Dovesi, R. Phys. Status Solidi 1993, 177, 157 .

(49) Gatti, C. TOPOND98 User's Manual; CNR-CSRSRC: Milano, Italy, 1998.

(50) Keith, T. A. Ph.D. Thesis, McMaster University, Ontario, Canada, 1993.

(51) Macchi, P.; Sironi, A. Coord. Chem. Rev. 2003, 238-239, 383.

(52) Cortés-Guzmán, F.; Bader, R. F. W. Coord. Chem. Rev. 2005, 249 , 633.

(53) Espinosa, E.; Alkorta, I.; Elguero, J.; Molins, E. J. Chem. Phys. 2002, 117, 5528 .

(54) Gibbs, G. V.; Cox, D. F.; Crawford, T. D.; Rosso, K. M.; Ross, N. L. J. Chem. Phys., submitted for publication.

(55) Gibbs, G. V.; Hill, F. C.; Boisen, M. B. Phys. Chem. Miner. 1997, $24,167$.

(56) Bader, R. F. W.; Essén, H. J. Chem. Phys. 1984, 80, 1943. 60 .

(58) Cremer, D.; Kraka, E. Croat. Chem. Acta 1984, 57, 1259.

(59) Shannon, R. D.; Prewitt, C. T. Acta Crystallogr., Sect. B 1969, 25 , 925.

(60) Shannon, R. D. In Structure and Bonding in Crystals II; O'Keeffe, M., Navrotsky, A., Eds.; Academic Press: New York, 1981; p 53. 